\title{
MÉTODOS PARA ANÁLISE DE ÁCIDO CLOROGÊNICO
}

\author{
Carlos Alberto Bastos De Maria* e Ricardo Felipe Alves Moreira \\ Departamento de Ciências Fisiológicas, Instituto Biomédico, Universidade do Rio de Janeiro, Rua Frei Caneca, 94, \\ 20211-040 Rio de Janeiro - RJ
}

Recebido em 11/12/02; aceito em 1/4/04; publicado na web em 27/05/04

\begin{abstract}
ANALYTICAL METHODS FOR CHLOROGENIC ACID. This paper describes the analytical methods for determination of total chlorogenic acid (CGA) and their individual isomers. Spectrofotometric methods are adequate for total CGA analysis in green coffee but they can provide inflated results for coffee products. High pressure liquid chromatography (HPLC) with gel permeation column and ultraviolet (UV) monitoring is adequate for the simultaneous analysis of total CGA, alkaloids and sugars in coffee products. HPLC-UV-reversed phase is a simple, rapid and precise method for the determination of the individual isomers of CGA. Gas chromatography (GC) also is applied to the analysis of the individual isomers but phenolic acids need to be derivatized before analysis. Both HPLC- and GC-mass spectrometry provide an unequivocal identification of the individual isomers. The capillary electrophoresis method is simple, rapid and adequate to the simultaneous analysis of polyphenols and xanthines. Advantages and limitations of each method are discussed throughout the text.
\end{abstract}

Keywords: total chlorogenic acid; individual isomers; analytical methods.

\section{INTRODUÇÃO}

O termo ácido clorogênico (ACG) parece ter sido introduzido em 1846 por Payen ${ }^{1}$ para designar um composto fenólico com função ácida, de estrutura ainda desconhecida, que conferia cor verde ao meio aquoso quando em meio levemente alcalino e exposto ao ar. Esse ácido foi isolado em $1907^{2}$ na forma de um complexo cristalino, denominado clorogenato de cafeína, a partir do qual se preparou um ácido puro. A estrutura química para este composto foi estabelecida por Fischer ${ }^{3}$ como ácido 3-cafeoilquínico (atualmente conhecido como ácido 5-cafeoilquínico). Mais tarde, outros compostos fenólicos ácidos foram isolados, caracterizados quanto à estrutura química e agrupados na mesma família ${ }^{4}$. Atualmente, o termo ACG é usado para designar uma família de ésteres formados pela esterificação de um ou mais derivados do ácido trans-cinâmico (Figura 1a) com o ácido quínico (ácido $1 \mathrm{~L}-1(\mathrm{OH}), 3,4,5$ - tetra-hidroxiciclohexanóico); este último tem hidroxilas na posição axial nos carbonos 1 e 3 e hidroxilas equatoriais nos carbonos 4 e 5 (Figura 1b). Os isômeros cis dos derivados do ácido cinâmico já foram detectados em produtos processados, porém não têm sido detectados naqueles in natura ${ }^{5}$. Esses compostos fenólicos podem ser subdivididos pela identidade do derivado do ácido cinâmico, número e posição dos resíduos acila. Os grupos majoritários (Figura 1e), encontrados na natureza, estão relacionados abaixo:

1- éster do ácido cafêico (Figura 1c) com o ácido quínico (ácido cafeoilquínico - ACQ) (isômeros 3-, 4-, 5-)

2- éster de dois resíduos do ácido cafêico com um de ácido quínico (ácido dicafeoilquínico - diACQ) (isômeros 3,4-, 3,5-, 4,5-)

3- éster do ácido ferúlico (Figura 1d) com o ácido quínico (ácido feruloilquínico - AFQ) (isômeros 3-, 4-, 5-).

O grupo mais abundante na natureza é o ACQ e, portanto, existe uma extensa literatura a seu respeito. Em suas revisões Clifford ${ }^{5,6}$ descreveu a presença de triACQ e tetraACQ na família Asteraceae. Em algumas famílias foram descritos os ácidos sinapoilquínicos, os

*e-mail: carreb@uol.com.br

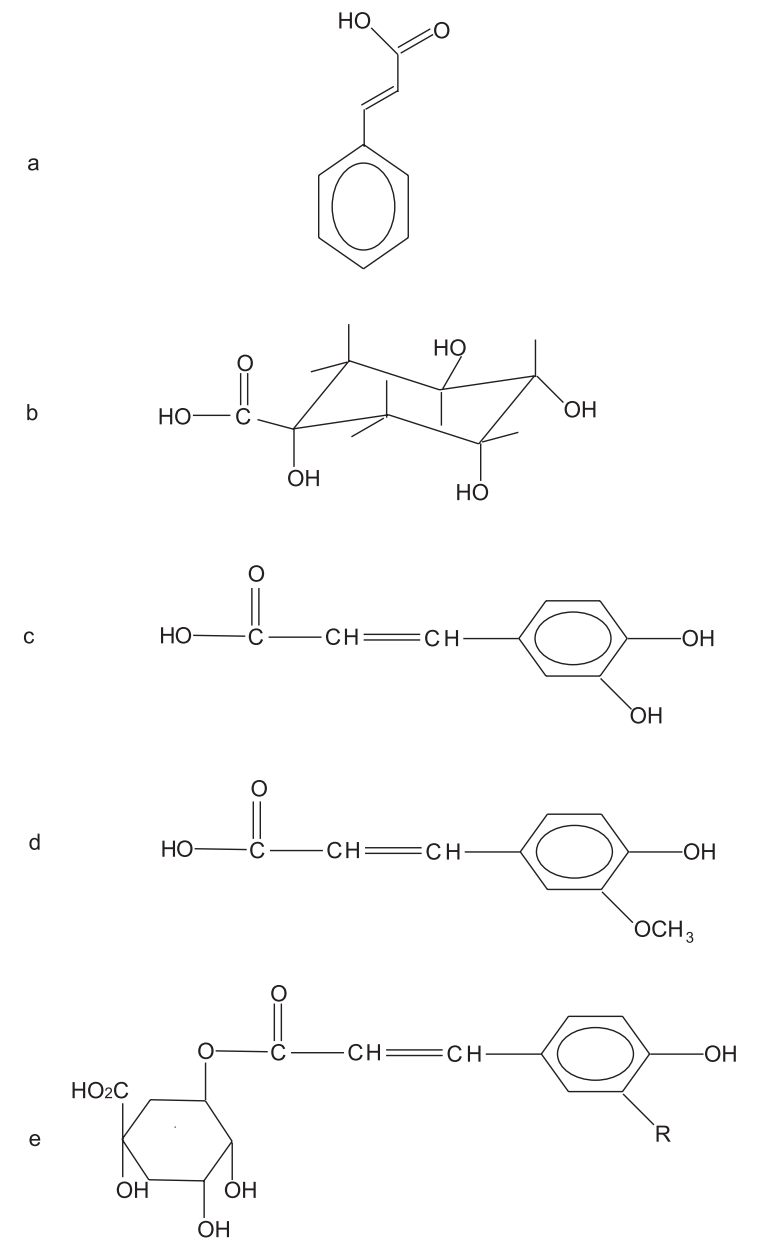

Figura 1. Estrutura dos isomeros do $A C Q$ e $A F Q$ : a) ácido trans-cinâmico; b) $D$-(-)-ácido quínico; c) ácido cafêico; d) ácido ferúlico e e) $\mathrm{R}=\mathrm{OH}$, ácido 5-cafeoilquínico, $\mathrm{R}=\mathrm{OCH}_{3}$, ácido 5-feruloilquínico. A esterificação também é possível nos átomos do carbono 3,4 do ácido quínico 
cumaroilquínicos e os conjugados do ácido cafêico com diácidos alifáticos (ex. ácidos oxálico e succínico) e com o ácido quínico. Esses grupos têm representação restrita e são muito pouco estudados. Nesta revisão, somente serão abordados os métodos de análise para os ACQ, diACQ e AFQ. É importante enfatizar que será usada, ao longo desta revisão, a nomenclatura da IUPAC ${ }^{7}$, que identifica o representante majoritário da família ACG, na natureza, como o 5ACQ, cuja recomendação é de que a numeração deva seguir a direção onde há o maior número de substituintes no anel do ácido quínico (Figura 1). Entretanto, alguns autores insistem em descrever o 5$\mathrm{ACQ}$, principalmente por questão histórica, como 3-ACQ ou mesmo ACG, termos estes bastante usados antes da sistematização pela IUPAC. Os nomes triviais também são usados para isômeros de outros grupos, no entanto, de uso bem mais restrito. Na Tabela 1, são listados os nomes triviais para ACQ e diACQ. Nesta revisão, o termo ACG será usado para designar o conjunto de isômeros dos grupos ACQ, diACQ e AFQ presente em uma matriz.

Tabela 1. Nomes triviais para isômeros do ACQ e diACQ

\begin{tabular}{cc}
\hline & Nomes \\
\hline IUPAC & Trivial \\
\hline 3-ACQ & $\begin{array}{c}\text { Ácido clorogênico* } \\
\text { 4-ACQ }\end{array}$ \\
5-ACQ & Ácido criptoclorogênico, banda 510 \\
& $\begin{array}{c}\text { Ácidos: isoclorogênico, neoclorogênico, } \\
\text { clorogênico (ainda bastante usado) }\end{array}$ \\
Mistura dos isômeros: & Ácido isoclorogênico \\
$3,4-; 3,5-; 4,5-d i A C Q$ &
\end{tabular}

*Alguns autores ainda insistem em usar esse nome trivial para o 3ACQ, enquanto a maioria dos autores usa o mesmo termo para designar o 5-ACQ; ACQ - ácido cafeoilquínico; diACQ - ácido dicafeoilquínico. Informações baseadas nas refs. 7 e 29.

O ACG é encontrado em uma gama de alimentos de origem vegetal. O café é uma das principais fontes de ACG na dieta humana e uma xícara da bebida $(200 \mathrm{~mL})$ pode conter cerca de 20-675 mg, dependendo da espécie de café e das condições de processamento ${ }^{5}$. Já a batata inglesa pode fornecer de 50-120 mg de ACG por $100 \mathrm{~g}$ de matéria seca. A maçã é um dos frutos mais estudados, podendo conter de 6,2-38,5 mg \% de ACQ, enquanto o tomate contém em torno de 1-8 $\mathrm{mg} \%{ }^{5}$. Um grupo de frutos tropicais foi analisado quanto ao teor de ACQ, AFQ e diACQ na casca, polpa e semente ${ }^{8}$. O 5-ACQ foi o isômero encontrado em maior quantidade nos frutos, independente da parte do fruto analisada. De modo geral, as sementes contêm um teor muito baixo de ACQ. A casca da jaca apresentou quantidade expressiva de 5ACQ (1300 mg \%). Por outro lado, a polpa do marmeleiro foi a mais rica (173 mg \%), enquanto a do abiu (47,3 mg \%) e a da graviola (47,4 $\mathrm{mg} \%$ ) mostraram valores mais baixos ${ }^{8}$.

Uma amplitude de funções nas plantas tem sido relacionada à presença de ACG. Clifford e Ohiokpehai ${ }^{9}$ encontraram evidências das propriedades adstringentes do diCQA, que influenciaram negativamente a aceitabilidade da bebida de café. Já o 5-ACQ parece inibir a atividade das enzimas ácido indolacético oxidase $\mathrm{e}^{5,10} \mathrm{e}$ fosforilase ${ }^{11}$, relacionadas ao fim do estágio de dormência e ao início do processo de desenvolvimento da planta.

A partir da década de 80 , os efeitos protetores e deletérios do ACG, particularmente o 5-ACQ, sobre células de espécies do reino animal, foram abordados em diferentes trabalhos. Alguns autores mostraram que o 5-ACQ foi um agente indutor de alterações no DNA de mamíferos ${ }^{12}$. Já Ohnishi e colaboradores ${ }^{13}$ verificaram seu efeito antioxidante na redução da hemólise e da peroxidação de hemácias de ratos, induzida por $\mathrm{H}_{2} \mathrm{O}_{2}$. Essa ação antioxidante é devida à pre- sença de um grupamento orto-di-hidroxila no anel aromático do ácido cafêico (Figura 1c), que atuaria como um aceptor de radicais livres $^{14}$. De fato, a oxidação in vitro de LDL (lipoproteína de baixa densidade) humana foi retardada na presença de ácido cafêico ${ }^{15}$. O ACG pode ser facilmente oxidado por polifenoloxidases a o-quinonas, que poderiam interagir com grupamento $\mathrm{NH}_{2}$ de aminoácidos protêicos reduzindo o valor nutricional dos alimentos ${ }^{16}$. Em outro trabalho, foi relatado que o 5-ACQ inibiu as enzimas $\alpha$-amilases, tripsina e lisozima, através da formação de ligação covalente com resíduos de triptofano e cisteína ${ }^{17}$. Por outro lado, este isômero mostrou propriedades anti-inflamatórias devido a sua capacidade de inibição do processo inflamatório mediado por citocinas ${ }^{18}$. Já o consumo de altas doses de 5-ACQ, presentes na bebida de café, aumentou os níveis de homocisteína no plasma de humanos ${ }^{19}$. Esse aminoácido não protêico é um dos fatores de risco para o surgimento de doenças cardiovasculares. Essa variedade de efeitos benéficos e maléficos atribuída ao ACG, preponderantemente ao 5-ACQ, tem encorajado muitos pesquisadores a trabalhar com essa família de compostos fenólicos.

A escolha de um método de análise adequado para se desenvolver estudos com esses componentes é de suma importância. O objetivo desta revisão é apresentar uma abordagem crítica dos métodos analíticos disponíveis para determinação do conteúdo de ACG total e dos isômeros individuais do ACQ, diACQ e AFQ.

\section{MÉTODOS ANALÍTICOS}

\section{Gravimetria e volumetria}

O primeiro método analítico desenvolvido para quantificação da família ACG em plantas foi publicado por Charaux ${ }^{20}$. Seu método foi baseado na precipitação seletiva do ACG com sal de chumbo neutro, hidrólise ácida do clorogenato de chumbo, saponificação e extração com éter. Após a evaporação do éter, o conteúdo de ACG foi determinado por gravimetria. Até o final da década de 30, o método gravimétrico desenvolvido por Charaux ${ }^{20}$ foi o mais usado para a análise semi-quantitativa do conteúdo de ACG. Slotta e Neisser ${ }^{21}$ desenvolveram um método volumétrico semi-quantitativo que consistiu na extração aquosa do café seco e desengordurado, precipitação com acetato de chumbo neutro e hidrólise do clorogenato de chumbo com ácido sulfúrico. Em seguida, foi adicionada uma solução de iodo e a geração de iodato ocorreu pela adição posterior de hidróxido de sódio. A solução então foi titulada com tiossulfato de sódio. O maior problema com esse método volumétrico foi a reação de outros compostos fenólicos, produtos da pirólise de glicídios, com o iodo, causando uma superestimativa do conteúdo de ACG.

\section{Espectrofotometria}

Moores e colaboradores ${ }^{22}$ desenvolveram um método espectrofotométrico de baixo custo para análise de ACG em cafés verde (não processado) e torrado, baseado na absorção seletiva destes compostos na região do espectro de ondas eletromagnéticas conhecida como ultravioleta (UV). Inicialmente, a matriz desengordurada foi submetida à extração aquosa e, em seguida, foi feita uma análise da absorvância no comprimento de onda de $324 \mathrm{~nm}$. Posteriormente, foi adicionado acetato de chumbo básico ao extrato aquoso de café resultando na precipitação do clorogenato de chumbo. Eles verificaram que, após a precipitação com acetato de chumbo, cerca de $98 \%$ da absorção no comprimento de onda de $324 \mathrm{~nm}$, no extrato do café verde, foi perdida indicando que a absorção neste comprimento de onda foi devida à presença de compostos da família $\mathrm{ACG}^{22}$. No caso do café torrado, mesmo após a precipitação, permanecia no extrato 
uma fração que absorvia no comprimento de onda de $324 \mathrm{~nm}$, composta de produtos formados durante o processamento térmico. Conseqüentemente, o conteúdo de ACG no café torrado foi determinado pela diferença na absorção no comprimento de onda de $324 \mathrm{~nm}$ antes e após a precipitação com acetato de chumbo. Após pequenas modificações, introduzidas por Weiss ${ }^{23}$, particularmente a adoção de um fator de correção de $0,002 \mathrm{mg} / \mathrm{mL}$ para corrigir a pequena quantidade de clorogenato de chumbo solúvel no meio, o método espectrofotométrico de absorção do UV foi adotado oficialmente pela "Association of Official Analytical Chemists" (AOAC) ${ }^{24}$. Clifford e Wight $^{25,26}$ usaram a espectrofotometria de absorção da luz visível e do UV para determinação quantitativa de ACG total e ACQ em café. Eles observaram que uma solução aquosa de metaperiodato de sódio reagiu com o-, p-dihidroxi-fenóis (ACQ) e seus monometil-éteres (AFQ) produzindo naftoquinonas, as quais foram detectadas no comprimento de onda de $406 \mathrm{~nm}^{25}$. Clifford e Wight ${ }^{26}$ verificaram que os produtos da reação de uma solução aquosa de molibdato de sódio e sais de fosfato com o ACQ, diACQ e o ácido cafêico livre absorviam seletivamente nos comprimentos de onda de $370 \mathrm{~nm}$ (ACQ + diACQ) e $353 \mathrm{~nm}$ (ácido cafêico). A diferença entre o resultado obtido com o reagente metaperiodato (ACG total) e o obtido com o reagente molibdato (ACQ + diACQ) permitiu a estimativa do conteúdo de AFQ no café26.

\section{Cromatografias em papel, adsorção e camada delgada}

A partir da década de 50, houve a necessidade de se desenvolver método adequado à análise de isômeros individuais, particularmente dos grupos ACQ e AFQ, cujas estruturas químicas já tinham sido elucidadas. A cromatografia em papel foi uma das técnicas usadas para a resolução de isômeros individuais ${ }^{27}$. A quantificação dos isômeros do ACQ e AFQ foi conduzida, principalmente, pela análise da absorvância na região do UV $(\lambda=310-330 \mathrm{~nm})$. Um outro método foi baseado na separação dos isômeros por cromatografia de adsorção sobre sílica ${ }^{28}$. A quantificação foi conduzida com base na análise da absorvância do UV ( $\lambda=325-330 \mathrm{~nm})$. Esse método permitiu separar pela primeira vez um grupo de isômeros do ACG, denominado ácido isoclorogênico, o qual foi caracterizado pela espectroscopia por ressonância magnética nuclear como 3,4-diACQ, 3,5-diACQ e 4,5-diACQ. Embora a cromatografia de adsorção sobre sílica tenha maior precisão que a cromatografia em papel, ambos os métodos têm aplicação limitada, particularmente porque são extremamente tediosos e somente semi-quantitativos quando aplicados a matrizes com teor baixo de compostos fenólicos. Grodzinska-Zachwieja e colaboradores ${ }^{29}$ descreveram um método para separação dos isômeros do grupo ACQ, baseado na cromatografia em camada delgada sobre placas com sílica gel. A revelação dos isômeros foi conduzida com uma solução aquosa de nitrato e molibdato de sódio. O método separa satisfatoriamente os 3 isômeros do ACQ, porém consome muito tempo de análise.

\section{Cromatografia gasosa (CG)}

A CG foi usada pela primeira vez no ano de $1958^{30}$ para análise de isômeros individuais do ACQ e diACQ. O extrato aquoso de café foi liofilizado e, em seguida, submetido à reação de derivatização com trimetil-cloro-silano ou hexametil-disilazano. O extrato de café foi, então, injetado diretamente em uma coluna recheada de CG. A separação dos ACQ e diACQ foi razoável, porém a análise demorada. A quantificação dos compostos fenólicos foi conduzida por padronização externa, sendo a detecção realizada com o auxílio de um detector de ionização em chama (DIC). Os isômeros do ACG derivatizados foram identificados pela CG acoplada à espectrometria de massas (EM). Em um outro trabalho, houve maior precisão na análise dos isômeros do ACQ e diACQ, quando os compostos fenólicos foram derivatizados com trimetil-silil-acetamida ${ }^{31}$.

Com o desenvolvimento da coluna capilar de sílica fundida para aplicação em CG, houve um grande avanço na análise de isômeros individuais do $\mathrm{ACG}^{32}$. Comparada à coluna recheada, a coluna capilar de vidro e, principalmente, a de sílica fundida propiciaram uma redução do volume de injeção da amostra, bem como melhor resolução dos isômeros e um menor tempo de análise. Hughes e Thorpe ${ }^{32}$ derivatizaram extratos de café e procederam à identificação e quantificação dos isômeros do ACQ e do diACQ pela CG/EM e CG/ DIC, respectivamente.

\section{Cromatografia líquida de alta eficiência (CLAE)}

\section{$C L A E-U V$}

A partir da metade da década de 70, com a introdução da CLAE, houve um grande avanço na análise de isômeros individuais do ACG em extratos vegetais. Rees e Theaker ${ }^{33}$ usaram a CLAE para a análise de alguns isômeros individuais do ACQ, diACQ e AFQ em amostras de café. A coluna do tipo fase reversa (apolar) consistiu de sílica, com partículas de $40 \mu \mathrm{m}$, parcialmente modificada pela ligação covalente com octadecilsilano (ODS). Essa fase estacionária confere apolaridade ao suporte, porém como a ligação química não ocorre em toda a sua extensão, uma quantidade razoável de sítios silanol permanece inalterada, permitindo a melhor separação dos isômeros 3-AFQ e 4-ACQ. Rees e Theaker ${ }^{33}$ usaram uma bomba de pressão constante e um detector de absorvância na região do UV $(\lambda=325 \mathrm{~nm})$. Esses autores separaram os isômeros do diACQ com uma fase móvel composta de ácido propiônico e água. Já o 5-ACQ e o 3-AFQ foram separados com uma fase móvel consistindo de ácido fórmico, ácido acético e água. Os maiores inconvenientes deste método foram a necessidade de 2 corridas cromatográficas, o número baixo de pratos da coluna devido ao tamanho da partícula do suporte e o uso de uma bomba de pressão constante, que não compensa as variações de vazão da fase móvel. Court $^{34}$ usou uma fase móvel composta de metanol e solução aquosa de di-hidrogeno-fosfato de potássio $(0,1 \mathrm{M})$ para separar compostos fenólicos em tabaco. Ele usou um sistema gradiente, onde a concentração do metanol aumentou de 20 para $70 \%$ em 60 min, conseguindo separar a maioria dos isômeros do ACQ, diACQ e AFQ em uma única corrida cromatográfica. William e colaboradores ${ }^{35}$ usaram a CLAE para análise de isômeros do ACQ e do diACQ em amostras de batata doce. A fase móvel, a coluna de fase apolar e o comprimento de onda $(\lambda=313 \mathrm{~nm})$ foram similares aos usados por Court $^{34}$. A grande novidade do método de William e colaboradores ${ }^{35}$ foi o isolamento dos compostos fenólicos por extração em fase sólida, cuja coluna continha o mesmo material da coluna analítica. Esses compostos então foram dessorvidos seletivamente com um sistema de solvente contendo acetonitrila/metanol/ água.

Com o desenvolvimento de fases estacionárias contendo micropartículas $(5 \mu \mathrm{m})$, houve um grande avanço na análise de ACG pela CLAE. Esse tipo de fase estacionária permitiu a separação completa de todos os isômeros do ACG. Na Figura 2 é apresentado um cromatograma típico dos isômeros do ACQ e AFQ em extrato de café, obtido através da CLAE. Van der Stegen e Van Duijn ${ }^{36}$ usaram uma coluna de fase apolar ODS, composta de micropartículas e conseguiram quantificar todos os isômeros do ACQ, diACQ e AFQ, em extratos de café, numa única corrida cromatográfica. Esses autores usaram um gradiente de metanol em solução aquosa de citrato de tripotássio $(\mathrm{pH}=2,5)$ como fase móvel. Trugo e Macrae ${ }^{37}$ usaram condições cromatográficas similares às de Van der Stegen e Van Duijn ${ }^{36}$, porém descreveram que a extração com metanol/água (40/60, v/v), seguida pela clarificação do extrato com reagente de Carrez 


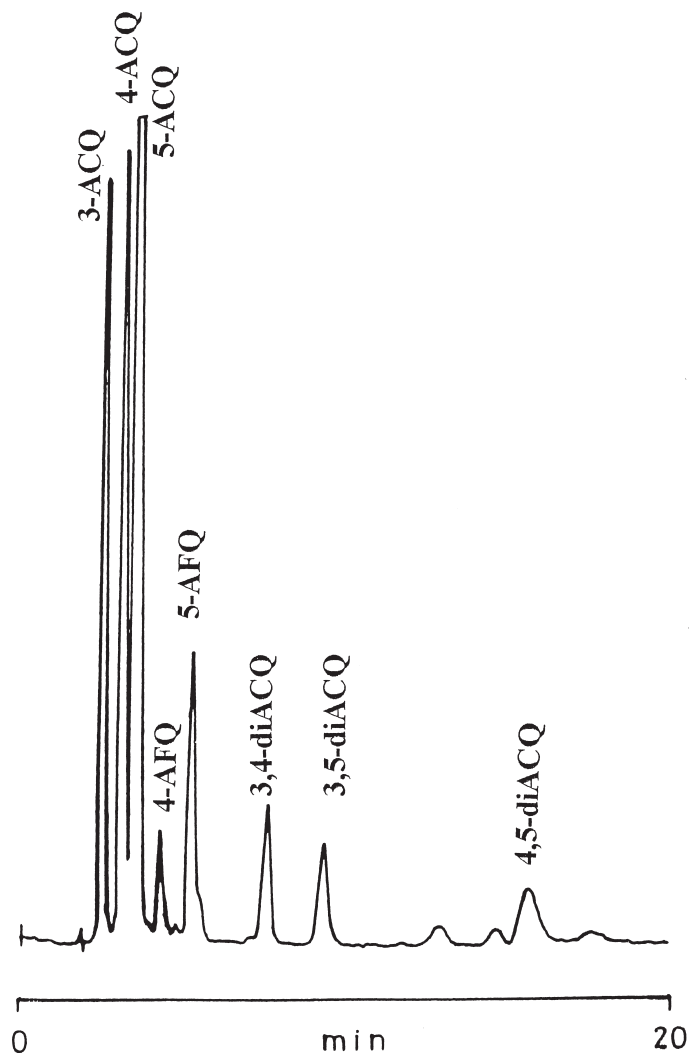

Figura 2. Cromatograma típico dos isômeros de ACG obtidos pela CLAEUV. Fase móvel: metanol-citrato tri-sódio 0,01M (40:60, v/v) - pH=2,3. Detecção: $325 \mathrm{~nm}$. $A C Q$ = ácido cafeoilquínico. diACQ = ácido dicafeoilquínico. $A F Q=$ ácido feruloilquínico

(ferrocianeto de potássio + acetato de zinco), foi o método mais adequado para a extração dos isômeros do ACG em cafés torrado e solúvel. De fato, Ky ecolaboradores ${ }^{38}$, comparando 5 métodos de extração de ACG presente em café, concluíram que o método de Trugo e Macrae $^{37}$ foi o mais adequado no que diz respeito aos parâmetros repetibilidade, precisão, rapidez e baixo custo da análise. Eles verificaram que o uso de extrações sucessivas com éter de petróleo, clorofórmio e acetato de etila aumentou as perdas de ACG e não foi adequado para a análise de rotina. O uso de cartucho Sep-Pak para extração em fase sólida causou uma imprecisão na análise, já que os isômeros individuais do ACQ e AFQ ficaram fortemente adsorvidos na matriz de octadecilsílica. Já a extração com água quente produziu a perda parcial de isômeros do grupo do diACQ. Ky e colaboradores $^{38}$ também constataram que o uso do reagente de Carrez foi fundamental para a precipitação de material coloidal, particularmente proteínas e polissacarídeos, que formam complexos com o ACG em pH ácido. Trugo e Macrae ${ }^{37}$ usaram o coeficiente de absortividade molar de cada isômero do ACG, já descrito na literatura ${ }^{39}$, para determinar a concentração de cada isômero no café, baseado no fator de resposta de um padrão autêntico de 5-ACQ. Esse artifício é importante, já que os isômeros puros do diACQ, AFQ, 3-ACQ e 4-ACQ não estão disponíveis para venda. O comprimento máximo de absorção para todos os isômeros ficou entre $325-330 \mathrm{~nm}$, portanto, o uso do comprimento de onda de $325 \mathrm{~nm}$ produziu um erro aceitável (máximo de $2 \%$ ). Na Tabela 2, é apresentado o coeficiente de absortividade molar dos isômeros do ACQ, diACQ e AFQ. Balyaya e Clifford ${ }^{40}$ também usaram a CLAE para a análise de isômeros individuais do ACG em extratos de café. Eles utilizaram coluna de fase apolar e fase móvel, no modo gradiente (100\% do solvente A para $100 \%$ do solvente B em 56 min), composta de solvente A - solução aquosa de ácido trifluoracético $(0,5 \%, \mathrm{v} / \mathrm{v})$ e solvente B - acetonitrila. Esse método é vantajoso para a obtenção de padrões puros, já que a fase móvel é facilmente removida por evaporação. Entretanto, a vida útil da coluna é menor, em função do $\mathrm{pH}$ muito baixo da fase móvel $(\mathrm{pH} \cong 2$ ).

Tabela 2. Coeficiente de absortividade molar de isômeros do ACG $\left(\mathrm{x} 10^{4} \mathrm{~mol} \mathrm{~L}^{-1}\right)$

\begin{tabular}{lccc}
\hline Compostos & $\lambda=330 \mathrm{~nm}$ & Compostos & $\lambda=325 \mathrm{~nm}$ \\
\hline 3-ACQ & 1,84 & 3-AFQ & 1,93 \\
4-ACQ & 1,80 & 4-AFQ & 1,95 \\
5-ACQ & 1,95 & 5-AFQ & 1,90 \\
3,4-diACQ & 3,18 & & \\
3,5-diACQ & 3,16 & & \\
4,5-diACQ & 3,32 & & \\
\hline
\end{tabular}

ACQ - ácido cafeoilquínico; diACQ - ácido dicafeoilquínico; AFQ - ácido feruloilquínico. Informações baseadas na ref. 39.

O emprego de detectores que permitiram a análise da absorvância em todos os comprimentos de onda da região do UV, em uma única corrida cromatográfica, aumentou a precisão da CLAE. O DAD ("diode array detector") tem sido usado para a análise de compostos fenólicos em plantas ${ }^{41-43}$ e plasma de ratos $^{44}$. A determinação simultânea de 5-ACQ, epicatequina e isoquercitrina em plasma de ratos foi conduzida pela análise da absorvância nos comprimentos de onda de 325,278 e $360 \mathrm{~nm}$, respectivamente ${ }^{44}$. O limite de detecção do 5ACQ foi de $0,04 \mu \mathrm{g} / \mathrm{mL}$ de plasma. A grande vantagem do DAD é que os isômeros de cada grupo podem ser analisados no comprimento de onda específico onde ocorre o máximo de absorção de cada componente. Entretanto, esses detectores têm um custo mais elevado em comparação aos detectores de UV convencionais. A sensibilidade da detecção no UV tem sido aumentada consideravelmente pelo processo de derivatização pré- ou pós-coluna. Neste caso, o analito é convertido a um derivado químico cujo nível de absorção é maior que o composto original. Bandoniene e Murkovic ${ }^{45}$ usaram a CLAE com derivatização pós-coluna com o radical 2,2'-difenila-1picrilhidrazila, para a determinação da capacidade antioxidativa de compostos fenólicos. A análise foi baseada na redução da absorção no comprimento de onda de $515 \mathrm{~nm}$. Quanto menor a absorção, maior a atividade antioxidante do composto. Esta técnica é muito pouco usada em função da necessidade de se fazer um processo de derivatização específico para cada analito.

\section{CLAE-UV e CLAE-IR (índice de refração) com coluna de permeação em gel}

Foram publicados alguns artigos enfocando a análise simultânea de cafeína, ACG total, trigonelina e sacarose em café através da CLAE com coluna de permeação em gel ${ }^{46-48}$. O desenvolvimento de fase estacionária estável mecanicamente, isto é, resistente a pressões usadas na CLAE, permitiu o uso da coluna de permeação em gel neste tipo de cromatografia. Os compostos foram separados em uma coluna do tipo TSK G3000-SW. Esta coluna é adequada para separação de componentes com massa molecular (MM) em torno de 1.000300.000. Entretanto, os isômeros do ACG, a cafeína, a trigonelina e a sacarose apresentam uma MM de cerca de 100-700. Embora esses componentes tenham uma MM muito baixa, a resolução entre eles foi satisfatória, indicando que houve algum outro fenômeno além da permeação em gel. Foi sugerida a ocorrência de interações hidrofóbicas, que contribuiriam para a adsorção desses componentes ${ }^{46}$. O método foi aplicado então para análise de: 1- cafeína e ACG total em café solúvel com detecção no UV $(\lambda=280 \mathrm{~nm})^{46}$; 2- cafeína, trigonelina e ACG total em café verde com detecção no UV 
$(\lambda=272 \mathrm{~nm})^{47}$ e 3 - cafeína, trigonelina, sacarose e ACG total em café verde com detecção em monitor de índice de refração ${ }^{48}$. Esse método ${ }^{46}$ foi comparado à cromatografia de fase reversa ${ }^{37} \mathrm{e}$ ao método da $\mathrm{AOAC}^{24}$ para análise de ACG total. O método CLAE com coluna de permeação em gel, aplicado à análise de ACG total em café verde, apresentou resultados com um alto nível de correlação $(r>0,9)$ com os da fase reversa e da AOAC. No entanto, no caso dos cafés torrado e solúvel, tanto o método com coluna de permeação em gel como o da fase reversa apresentaram resultados significativamente $(\mathrm{p}<0,01)$ mais baixos, quando comparados ao da AOAC. Isto sugere que o método da AOAC não é adequado para a análise quantitativa de ACG total em cafés processados.

\section{CLAE-EM}

O maior avanço no método da CLAE com coluna de fase apolar foi o seu acoplamento à EM. Este método hifenado permitiu conduzir estudos relacionados à distribuição dos isômeros do ACG em diferentes compartimentos biológicos, particularmente o sangue, onde o conteúdo de compostos fenólicos é extremamente baixo. Como já mencionado anteriormente, o 5-ACQ e o ácido cafêico são os mais estudados em função dos seus efeitos biológicos. Existe uma grande controvérsia se o ACG é absorvido intacto no trato gastrointestinal ${ }^{49}$, ou se é submetido à hidrólise por esterases ${ }^{50,51}$. Neste último caso, o ácido cafêico é o composto absorvido durante o processo de digestão e absorção. Dados preliminares indicam que o componente majoritário no sangue é o ácido cafêico e, portanto, caso o 5-ACQ seja absorvido intacto no trato gastrointestinal isso ocorreria em quantidade muito baixa $^{50,51}$. Esta informação reforça a importância do uso da CLAE-EM na análise de isômeros do ACG em compartimentos biológicos. Foram conduzidos alguns estudos para análise de ácido cafêico e 5-ACQ no plasma e na urina de seres humanos através da CLAE-EM com ionização por "electrospray" (IES) ${ }^{52}$. O método foi útil para monitorar alterações nos níveis desses compostos fenólicos induzidas pela dieta. Em relação à técnica de extração, numa matriz como o sangue repleta de colóides, o tratamento com betaglicuronidase ou hidrólise alcalina, seguido de extração com metanol ${ }^{51}$ ou mesmo extração com metanol sem hidrólise prévia ${ }^{49}$ é essencial para a extração eficiente dos compostos fenólicos. O primeiro método ${ }^{51}$ é interessante para distinguir os ácidos fenólicos livres (ex. ácido cafêico) associados a proteínas daqueles esterificados (ex. 5-ACQ) e, também, ligados a proteínas. A CLAE-EM também foi empregada para análise de compostos fenólicos em plantas ${ }^{53-56}$. Li e colaboradores ${ }^{53}$ isolaram polifenóis do tabaco através da extração em fase sólida e identificaram os compostos com CLAEIES-EM. Eles verificaram que a sensibilidade do método foi de $50 \mathrm{ng} /$ $\mathrm{mL}$ e $100 \mathrm{ng} / \mathrm{mL}$ para o ácido cafêico e o 5-ACQ, respectivamente. Carini e colaboradores ${ }^{55}$ usaram a CLAE/EM com uma interface de ionização química à pressão atmosférica (IQPA) para identificação de compostos fenólicos em plantas. A mesma técnica foi usada para análise de hidroxicinamatos e catequinas na urina de seres humanos ${ }^{57}$. A CLAE/IQPA-EM forneceu informações úteis sobre a massa molecular e a estrutura química dos compostos. Mais recentemente, a CLAE/ IES-EM/EM foi usada para a análise de 40 constituintes fenólicos em ameixas secas, incluindo isômeros do $\mathrm{ACQ}^{58}$. Esta técnica permitiu a identificação inequívoca de uma grande quantidade de compostos fenólicos. O 5-ACQ foi o composto fenólico predominante nessas $\operatorname{amostras}^{58}$.

Os espectros de massas dos isômeros do ACG foram investigados recentemente através da CLAE/EM ${ }^{\mathrm{n}}$ por Clifford e colaboradores ${ }^{59}$. A $\mathrm{CLAE} \mathrm{EM}^{1}, \mathrm{EM}^{2}, \mathrm{EM}^{3}, \mathrm{EM}^{4}$ permitiu a identificação inequívoca dos isômeros do ACQ, AFQ e diACQ. Na Tabela 3, são mostrados os principais fragmentos obtidos pela análise dos espectros de massas. Os isômeros 3-ACQ e 5-ACQ apresentaram padrões de fragmentação similares. A diferenciação foi possível pela $\mathrm{CLAE} / \mathrm{EM}^{2}$, onde o fragmento secundário $\mathrm{m} / \mathrm{z}=161,4$ foi identificado exclusivamente no espectro de massas do 5-ACQ. Um outro fato relevante foi a presença do fragmento $\mathrm{m} / \mathrm{z}=179,5$, o qual foi mais abundante no isômero 3ACQ (49) em comparação ao 5-ACQ (5). Em relação aos isômeros diACQ, a identificação inequívoca foi obtida pela CLAE-EM ${ }^{2}$, onde os fragmentos $\mathrm{m} / \mathrm{z}=173,5 \mathrm{e} \mathrm{m} / \mathrm{z}=335,6$ foram encontrados exclusivamente no espectro de massas do 3,4-diACQ (Tabela 3). Também

Tabela 3. Fragmentos obtidos por $\mathrm{LC}-\mathrm{EM}^{\mathrm{n}}$ para isômeros do ACG

\begin{tabular}{|c|c|c|c|c|c|c|c|c|c|c|c|c|}
\hline \multirow{4}{*}{$\begin{array}{l}\text { Compostos } \\
\text { 3-ACQ }\end{array}$} & \multirow{4}{*}{$\begin{array}{c}\begin{array}{c}\mathrm{EM}^{1} \\
\text { Íon } \\
\text { molecular }\end{array} \\
353,7\end{array}$} & \multicolumn{4}{|c|}{$\mathrm{EM}^{2}$} & \multicolumn{4}{|c|}{$\mathrm{EM}^{3}$} & \multicolumn{3}{|c|}{$\mathrm{EM}^{4}$} \\
\hline & & \multirow{2}{*}{$\begin{array}{l}\text { Íon } \\
\text { base }\end{array}$} & \multirow{2}{*}{\multicolumn{3}{|c|}{$\begin{array}{c}\text { Fragmentos } \\
\text { secundários }\end{array}$}} & \multirow{3}{*}{$\begin{array}{c}\begin{array}{c}\text { Íon } \\
\text { base }\end{array} \\
85,6\end{array}$} & \multirow{2}{*}{\multicolumn{3}{|c|}{$\frac{\text { Fragmentos }}{\text { secundários }}$}} & \multirow{2}{*}{$\begin{array}{l}\text { Ín } \\
\text { base }\end{array}$} & \multirow{2}{*}{\multicolumn{2}{|c|}{$\begin{array}{l}\text { Fragmentos } \\
\text { secundários }\end{array}$}} \\
\hline & & & & & & & & & & & & \\
\hline & & 191,5 & $\begin{array}{c}179,5 \\
(49)\end{array}$ & - & $\begin{array}{c}135,7 \\
(10)\end{array}$ & & $\begin{array}{c}127,1 \\
(93)\end{array}$ & $\begin{array}{c}172,3 \\
(60)\end{array}$ & - & - & - & - \\
\hline 4-ACQ & 353,5 & 173,5 & $\begin{array}{c}179,5 \\
(68)\end{array}$ & $\begin{array}{c}191,6 \\
(20)\end{array}$ & $\begin{array}{c}135,7 \\
(14)\end{array}$ & 93,3 & $\begin{array}{c}111,2 \\
(47)\end{array}$ & - & - & - & - & - \\
\hline 5-ACQ & 353,3 & 191,5 & $\begin{array}{c}179,5 \\
(5)\end{array}$ & $\begin{array}{c}161,4 \\
(2)\end{array}$ & - & 85,7 & $\begin{array}{c}127,1 \\
(93)\end{array}$ & $\begin{array}{r}172,2 \\
(75)\end{array}$ & - & - & - & - \\
\hline 3-AFQ & 367,5 & 193,5 & $\begin{array}{c}191,5 \\
(3)\end{array}$ & - & - & 134 & $\begin{array}{c}148,8 \\
(30)\end{array}$ & - & - & 106,5 & - & - \\
\hline 4-AFQ & 367,4 & 173,5 & $\begin{array}{c}191,8 \\
(87)\end{array}$ & - & - & 93,3 & $\begin{array}{c}111,5 \\
(44)\end{array}$ & - & - & - & - & - \\
\hline 5-AFQ & 367,6 & 191,6 & $\begin{array}{c}173,6 \\
(6)\end{array}$ & - & - & 85,6 & $\begin{array}{l}127,1 \\
(100)\end{array}$ & $\begin{array}{c}172,2 \\
(90)\end{array}$ & - & - & - & - \\
\hline 3,4-diACQ & 515,7 & 353,4 & $\begin{array}{c}335,6 \\
(16)\end{array}$ & $\begin{array}{c}173,5 \\
(18)\end{array}$ & - & 173,5 & $\begin{array}{c}179,5 \\
(91)\end{array}$ & $\begin{array}{c}191,7 \\
(53)\end{array}$ & $\begin{array}{c}135,6 \\
(14)\end{array}$ & 93,4 & $\begin{array}{l}111 \\
(70)\end{array}$ & $\begin{array}{c}172,9 \\
(2)\end{array}$ \\
\hline 3,5-diACQ & 515,2 & 353,5 & - & - & - & 191,5 & $\begin{array}{c}179,5 \\
(53)\end{array}$ & $\begin{array}{c}173,5 \\
(8)\end{array}$ & $\begin{array}{c}135,6 \\
(12)\end{array}$ & 85,5 & $\begin{array}{l}127 \\
(95)\end{array}$ & $\begin{array}{c}172,9 \\
(90)\end{array}$ \\
\hline 4,5-diACQ & 515,4 & 353,5 & - & - & - & 173,5 & $\begin{array}{c}179,4 \\
(80)\end{array}$ & $\begin{array}{c}191,6 \\
(27)\end{array}$ & $\begin{array}{c}135,7 \\
(12)\end{array}$ & 93,3 & $\begin{array}{l}111 \\
(38)\end{array}$ & $\begin{array}{c}172,9 \\
(15)\end{array}$ \\
\hline
\end{tabular}

ACQ - ácido cafeoilquínico; diACQ - ácido dicafeoilquínico; AFQ - ácido feruloilquínico; ( ) abundância relativa do fragmento. Informações baseadas na ref. 59 . 
contribuiu de forma relevante a CLAE-EM ${ }^{4}$, onde o fragmento $\mathrm{m} / \mathrm{z}=$ 111 foi mais abundante no isômero 3,4-diACQ (70) que no 4,5-diACQ (38). Os isômeros do AFQ também apresentaram padrões de fragmentação com alguma similaridade. A identificação foi melhor obtida pela CLAE-EM $^{3}$, onde o pico base do 3-AFQ e do 4-AFQ foi o $\mathrm{m} / \mathrm{z}=134$ e o $\mathrm{m} / \mathrm{z}=93,3$, respectivamente, enquanto no 5 -AFQ foi o $\mathrm{m} / \mathrm{z}=85,6$. Embora a CLAE-EM ${ }^{\mathrm{n}}$ aumente a potencialidade da técnica no que diz respeito à identificação estrutural dos compostos, ela reduz a sensibilidade do método.

\section{Eletroforese capilar}

A eletroforese capilar também foi aplicada para a análise de compostos fenólicos em plantas ${ }^{60-64}$. O 5-ACQ é o isômero do ACG mais comumente analisado por este método. Sheu e colaboradores ${ }^{61}$ usaram a eletroforese por zona capilar para separar 12 compostos fenólicos, dentre eles o 5-ACQ. A detecção foi no comprimento de onda de $254 \mathrm{~nm}$. Vaher e Koel ${ }^{62}$ também separaram uma gama de compostos polifenólicos de diferentes plantas por eletroforese por zona capilar. Foi possível obter uma separação confiável de 5-ACQ, trans-resveratrol, catequina e quercetina usando-se tampão borato $\mathrm{e}$ acetonitrila. A cromatografia eletrocinética micelar foi empregada para análise simultânea de 5-ACQ e xantinas ${ }^{64}$. A separação dos compostos foi satisfatória. Cada composto foi coletado separadamente e identificado através da EM. A eletroforese capilar associada à EM permite um aumento na sensibilidade do método e a identificação inequívoca dos compostos, entretanto o tempo de análise é maior já que não é uma técnica hifenada.

\section{CONCLUSÃO}

Na Tabela 4, é apresentado um resumo dos principais métodos para análise de ACG. O método oficial da $\mathrm{AOAC}^{24}$ é barato e apre- senta resultados satisfatórios para análise de ACG total no café verde, entretanto, é tedioso e difícil de padronizar. O método espectrofotométrico de Clifford e Wight ${ }^{25,26}$ é simples, rápido e barato, sendo aplicado para a análise de ACG total e de ACQ + diACQ. Entretanto, esse método não permite a análise de isômeros individuais e nem fornece estimativa do conteúdo de diACQ. Em ambos os métodos espectrofotométricos, os resultados podem ser superestimados pela presença de interferentes.

O método de CG tem alta precisão e sensibilidade, particularmente a CG/EM. Entretanto, o maior inconveniente da CG, como método de análise de isômeros individuais do ACG, é a necessidade de derivatização desses compostos fenólicos para convertê-los em derivados voláteis, os quais passam totalmente à fase de vapor nas condições de temperatura usadas normalmente na CG.

Indubitavelmente, a CLAE é o método mais utilizado para a análise de isômeros individuais do ACG, tanto pela sua simplicidade e rapidez como também pela separação satisfatória dos isômeros. No caso somente da análise dos isômeros do ACQ e diACQ, 4-AFQ e 5AFQ em coluna de fase apolar, o modo isocrático pode ser usado com separação aceitável, o que permite um tempo de análise em torno de $20 \mathrm{~min}$. Neste caso, haverá uma superestimativa do 4-ACQ devido à coeluição com o 3-AFQ. Já o modo gradiente permite a análise de todos isômeros do ACQ, diACQ e AFQ, porém o tempo de análise chega a $40 \mathrm{~min}$. A grande vantagem da CLAE-UV com coluna de permeação em gel é a possibilidade da análise simultânea de vários compostos no café, o que favorece a automação da análise. Além disso, a fase móvel é a água, o que evita o uso de solventes tóxicos. Entretanto, no caso do ACG a técnica não permite a análise de isômeros individuais. Em relação aos detectores empregados na CLAE-UV, o DAD é o mais indicado porque aumenta a precisão e exatidão da análise de isômeros do ACG. O uso da CLAE/EM permite a análise de quantidades diminutas do ACG em plantas e fluidos biológicos, além de fornecer um diagnóstico da estrutura quími-

Tabela 4. Principais métodos para análise de ACG

\begin{tabular}{|c|c|c|c|}
\hline Método & Aplicação & Vantagens e desvantagens & Ref. \\
\hline \multicolumn{4}{|l|}{ ESPECTROFOTOMETRIA } \\
\hline Método AOAC & ACG total & $\begin{array}{l}\text { Superestimativa do teor de ACG, simples, barato, } \\
\text { demorado }\end{array}$ & 24 \\
\hline Método Clifford e Wight & $\begin{array}{l}\text { ACQ+diACQ, } \\
\text { estimativa do AFQ }\end{array}$ & $\begin{array}{l}\text { Simples, rápido, não fornece estimativa do teor } \\
\text { de diACQ }\end{array}$ & 25,26 \\
\hline \multicolumn{4}{|l|}{ CG } \\
\hline CG-DIC e CG-EM & Isômeros do ACG & $\begin{array}{l}\text { Exige derivatização dos compostos, dispendiosa, } \\
\text { boa precisão. A CG-EM auxilia na identificação } \\
\text { estrutural dos compostos }\end{array}$ & 32 \\
\hline \multicolumn{4}{|l|}{ CLAE } \\
\hline CLAE-UV-fase reversa & Isômeros do ACG & $\begin{array}{l}\text { Não exige derivatização, rápida, dispendiosa, } \\
\text { boa precisão, uso de solventes tóxicos }\end{array}$ & 37,40 \\
\hline CLAE-UV/IR permeação em gel & ACG total & $\begin{array}{l}\text { Análise simultânea de outros componentes do café, } \\
\text { dispendiosa, rápida, usa água como solvente }\end{array}$ & $46-48$ \\
\hline CLAE-EM & Isômeros do ACG & $\begin{array}{l}\text { Ótima precisão e exatidão, alta sensibilidade, } \\
\text { dispendiosa, auxilia na identificação estrutural } \\
\text { dos compostos }\end{array}$ & 54,58 \\
\hline \multicolumn{4}{|l|}{ ELETROFORESE } \\
\hline Eletroforese capilar & Isômeros do ACG & $\begin{array}{l}\text { Alta versatilidade, baixo custo, uso ainda } \\
\text { pouco difundido }\end{array}$ & 62,64 \\
\hline
\end{tabular}

$\mathrm{CG}=$ cromatografia gasosa; $\mathrm{DIC}=$ detector de ionização em chama; CLAE = cromatografia líquida de alta eficiência; UV = ultravioleta; IR = índice de refração; EM = espectrometria de massas 
ca dos compostos. A CLAE/EM não necessita de derivatização dos analitos e, portanto, é mais rápida que a $\mathrm{CG} / \mathrm{EM}$. O método é preciso e apresenta alta sensibilidade. Entretanto, o equipamento da CLAE/ EM é ainda mais caro que o da CG/EM. Com a redução do custo do equipamento, a CLAE-EM deverá ser uma das técnicas mais usadas para análise de isômeros do ACG.

A eletroforese capilar permite a separação de um grande número de compostos fenólicos com diferentes funções químicas. Além disso, a separação simultânea de compostos pertencentes a diferentes classes químicas, como é o caso das xantinas e compostos fenólicos, indica a grande versatilidade da técnica. Além do mais, a separação dos compostos pela eletroforese capilar com detecção pela EM tem um menor custo, em comparação à CLAE-EM. Entretanto, a análise pela CLAE-EM é mais rápida, já que é uma técnica hifenada. O método de eletroforese capilar é ainda pouco difundido, o que pode ser constatado pelo menor número de publicações científicas em comparação à CLAE.

\section{AGRADECIMENTOS}

Os autores agradecem o apoio da Fundação Carlos Chagas Filho de Amparo à Pesquisa do Rio de Janeiro (FAPERJ) e do Conselho Nacional de Desenvolvimento Científico e Tecnológico (CNPq).

\section{REFERÊNCIAS}

1. Payen; Ann. 1846, 60, 286

2. Gorter, K.; Ann. 1907, 358, 327

3. Fischer, H. O. L.; Dangschat, G.; Ber. 1932, 65B, 1037.

4. Sondheimer, E.; Szymanski, C. D.; Corse, J. W.; J. Agric. Food Chem. 1961, 9, 146.

5. Clifford, M. N.; J. Sci. Food Agric. 1999, 79, 362.

6. Clifford, M. N.; J. Sci. Food Agric. 2000, 80, 1033.

7. IUPAC; Biochem. J. 1976, 153, 23.

8. Pontes, P. V.; Moreira, R. F. A.; Trugo, L. C.; De Maria, C. A. B.; J. Sci. Food Agric. 2002, 82, 1177.

9. Clifford, M. N.; Ohiokpehai, O.; Anal. Proc. 1983, $20,83$.

10. Clifford, M. N. Em Coffee - botany, biochemistry and production ob beans and beverage; Clifford, M. N.; Wilson, R. C., eds.; Elsevier Applied Science Publishers: New York, 1985.

11. Clifford, M. N. Em Coffee vol. 1- Chemistry; Clarke, R. J.; Macrae, R., eds.; Elsevier Applied Science Publishers: New York, 1985.

12. Borish, E. T.; Cosgrove, J. P.; Church, D. F.; Deutsch, W. A.; Pryor, W. A.; Biochem. Biophys. Res. Commun. 1985, 133, 780.

13. Ohnishi, M.; Morishita, H.; Iwahashi, H.; Toda S.; Shirataki, Y.; Kimura, M.; Kido R.; Phytochemistry 1994, 36, 579.

14. Luzia, M. R.; Trugo, L. C.; da Paixão, K. C. C.; Marcílio, R.; De Maria, C. A. B.; Quinteiro, L. M. C.; Lebensm. Wiss. Technol. 1998, 31, 64.

15. Meyer, A. S.; Heinonen, M.; Frankel, E. N.; Food Chem. 1998, 61, 71.

16. Friedman, M.; J. Agric. Food Chem. 1997, 45, 1523.

17. Rohn, S.; Rawel, H. M.; Kroll, J.; J. Agric. Food Chem. 2002, 50, 3566.

18. Krakauer, T.; Immunopharmacol. Immunotoxicol. 2002, 24, 113.

19. Olthof, M. R.; Hollman, P. C.; Zock P. L.; Katan, M. B.; Am. J. Clin. Nutr. 2001, 73, 532

20. Charaux, C.; J. Pharm. Chim. 1910, 2, 292.

21. Slotta, K. H.; Neisser, K.; Ber. 1938, 71B, 1611.

22. Moores, R. G.; Mcdermott, D. L.; Wood, T. R.; Anal. Chem. 1948, 20, 620.
23. Weiss, L. C.; J. Ass. Off. Anal. Chem. 1953, 36, 663.

24. A.O.A.C.; Official Methods of Analysis, Association of Official Analytical Chemists, $14^{\text {th }}$ ed., Arlington, 1984.

25. Clifford, M. N.; Wight, J.; J. Chromatogr. 1973, 86, 222.

26. Clifford, M. N.; Wight, J.; J. Sci. Food Agric. 1976, 27, 73.

27. Pictet, G.; Brandenberger, H.; J. Chromatogr. 1960, 4, 396.

28. Corse, J.; Lundin, R. E.; Waiss, A. C. Jr.; Phytochemistry 1965, 4, 527.

29. Grodzinska-Zachwiesja, Z.; Kahl, W.; Warchol, A.; J. Chromatogr. 1967, $29,362$.

30. Langer, S. H.; Pantages, P.; Wender, I.; Chem. Ind. 1958, 1664.

31. Sabir, M. A.; Sosulski, F. W.; Finlanyson, A. J.; J. Agric. Food Chem. 1974, 22,575 .

32. Hughes, W. J.; Thorpe T. M.; J. Food Sci. 1987, 52, 1078.

33. Rees, D. I.; Theaker, P. D.; $8^{\text {th }}$ Colloque Scientifique International sur le Café, ASIC: Paris, 1977.

34. Court, W. A.; J. Chromatogr. 1977, 90, 287.

35. William, M. W. Jr.; Purcell, A. E.; McCollum, G. K.; J. Agric. Food Chem. 1979, 27, 938

36. Van der Stegen, G. H. D.; Van Duijn, J.; $9^{\text {th }}$ Colloque Scientifique International sur le Café, ASIC: Paris, 1980

37. Trugo, L. C; Macrae, R.; Analyst 1984, 109, 263.

38. Ky, C. L.; Noirot, M.; Hamon, S.; J. Agric. Food Chem. 1997, 45, 786.

39. Rubach, K.; Dissertation, Technische Universität Berlin, German, 1969.

40. Balyaya, K. J.; Clifford, M. N.; J. Food Sci. Technol. 1995, 32, 104.

41. Bilia, A. R.; Fumarola, M.; Gallori, S.; Mazzi, G.; Vincieri, F. F.; J. Agric. Food Chem. 2000, 48, 4734

42. Matilla, P.; Kumpulainen, J.; J. Agric. Food Chem. 2002, 50, 3660.

43. Dawes, H. M.; Keene, J. B.; J. Agric. Food Chem. 1999, 47, 2398.

44. Chang, Q.; Zhu, M.; Zuo, Z.; Chow, M.; Ho, W. K.; J. Chromatogr., B: Biomed. Sci. Appl. 2001, 760, 227.

45. Bandoniene, D.; Murkovic, M.; J. Agric. Food Chem. 2002, 50, 2482.

46. Trugo, L. C.; De Maria, C. A. B.; Werneck, C. C.; Food Chem. 1991, 42, 81.

47. De Maria, C. A. B.; Trugo, L. C.; Moreira, R. F. A.; Food Chem. 1995, $52,447$.

48. De Maria, C. A. B.; Trugo, L. C.; Corá, G.; Quim. Nova 1996, 19, 350.

49. Olthof, M. R.; Hollman, P. C.; Katan, M. B.; J. Nutr. 2001, 131, 66.

50. Azuma, K.; Ippoushi, K.; Nakayama, M.; Ito, H.; Higashio, H.; Terao, J.; J. Agric. Food Chem. 2000, 48, 5496.

51. Nardini, M.; Cirillo, E.; Natella, F.; Scaccini, C.; J. Agric. Food Chem. 2002, 50, 5735 .

52. Cremin, P.; Kasim-Karakas, S.; Waterhouse, A. L.; J. Agric. Food Chem. 2001, 49, 1747.

53. Li, Z.; Wang, L.; Yang, G.; Shi, H.; Jiang, C.; Liu, W.; Zhang, Y.; J. Chromatogr. Sci. 2003, 41, 36.

54. Dueñas, M.; Hernández, T.; Estrella, I.; Rabanal, R.; Food Chem. 2003, 82,373 .

55. Carini, M.; Aldini, G.; Furlanetto, S.; Stefani, R.; Facino, R. M.; J. Pharm. Biomed. Anal. 2001, 24, 517.

56. Tolonen, A.; Joutsamo, T.; Matilla, S.; Kamarainen, T.; Jalonen, J.; Phytochem. Anal. 2002, 13, 316

57. Nielsen, S. E.; Sandstrom, B.; J. Chromatogr., B: Biomed. Sci. Appl. 2003, $787,369$.

58. Fang, N.; Yu, S.; Prior, R. L.; J. Agric. Food Chem. 2002, 50, 3579.

59. Clifford, M. N.; Johnston, K. L.; Knight, S.; Kuhnert, N.; J. Agric. Food Chem. 2003, 51, 2900.

60. Spilkova, J.; Bednar, P.; Stroblikova, R.; Pharmazie 2001, 56, 424.

61. Sheu, S. J.; Chieh, C. L.; Weng, W. C.; J. Chromatogr. 2001, 911, 285.

62. Vaher, M.; Koel, M.; J. Chromatogr., A 2003, 990, 225.

63. Yang, X.; Han, F.M.; Cheng, Z.Y.; Chen, Y.; Se Pu. 1999, 17, 573.

64. Pomilio, A. B.; Trajtemberg, S.; Vitale, A. A.; Phytochem. Anal. 2002, 13, 235 . 